\title{
Prototyping a Learning Management System for Higher Education
}

\author{
Raafat George Saadé and Qiong Huang \\ Concordia University, John Molson School of Business, \\ Montreal, Quebec, Canada
}

\author{
rsinfo@sympatico.ca; Qiong.Huang@gmail.com
}

\begin{abstract}
This document presents a five year development initiative that sought to implement a learning management system clearly differentiated from the CMS domain. The present article reports on our research work showing our effort towards a design of a true learning management system which entails pedagogical strategies embedded into the system design and the online learning environment. This is characterized by its highly interactive and collaborative learning tools. The ability of the system to measure student effort and performance via the summation of the learning objects usage clearly differentiate the concept of true online learning from the traditional distance learning via content management systems.
\end{abstract}

Results from student usage of the learning management system provide some insight into learning, performance and behavior in online learning. Due to limitations only three learning objects were briefly analyzed to demonstrate their value to learning specifically and to the value of the system in general.

Keywords: Learning management systems, learning objects, collaboration, AJAX, OOD, online

\section{Introduction}

The past ten years has seen a rapid increase in Internet use. Institutions are being continuously subjected to pressures related to maintaining their web sites. The lack of proper management of out of date material, poor design and associated control of their web sites, lack of authority control and webmaster-created bottlenecks, ineffective assessment of efficiencies and effectiveness and weak development processes are just of few problems driving these pressures.

Today, the way the web is managed and maintained is evident. Unfortunately, it is characterized by highly manual approaches. The objective of a successful and sustainable web will have to be significantly automated. "Content Management Systems (CMS)" can be one vehicle serving this

Material published as part of this publication, either on-line or in print, is copyrighted by the Informing Science Institute. Permission to make digital or paper copy of part or all of these works for personal or classroom use is granted without fee provided that the copies are not made or distributed for profit or commercial advantage AND that copies 1) bear this notice in full and 2) give the full citation on the first page. It is permissible to abstract these works so long as credit is given. To copy in all other cases or to republish or to post on a server or to redistribute to lists requires specific permission and payment of a fee. Contact Publisher@InformingScience.org to request redistribution permission. objective. Institutional needs are highly customized and most agree that the solution to a specific CMS is a mixture of "buy\&build". The primary issue is to evaluate what we have to buy and how much should we build until we have what we need?

Literature from CMS vendors should be taken with a grain of salt due to the fact that they are over-hyped and filled with 
jargon. In fact the boundaries of the CMS concept are blurred and there is substantial overlap with other concepts such as document management systems, knowledge management systems, ecommerce systems, groupware, virtual learning environments and portals. There is yet to be a clear definition of what constitutes a CMS, and most of these systems claim to be a CMS.

The nature of the CMS is that it devolves control over content to the owner rather than the technician and scales without increasing management overheads. Educational institutions have expanded on the use of CMS to move away from the traditional in-class environment to the new digital phenomenon where teaching is assisted by computers (Richardson \& Swan, 2003), specifically CMSs. Today, we find a vast amount of courses, seminars, certificates and other educational offerings using the web. This wave of educational material offered online has challenged educational institutions with regards to the selection of the 100s of CMSs such First Class, WebCT, Moodle, eCollege and White Board, available in the market. At the same time, these institutions are struggling to redefine and restructure their strategies in providing educational content and its mode of delivering it (Association of European Universities, 1996). When it comes to measuring performance and learning, institutions have found that these content management systems have limited success, as is the case at the university of the authors of this article.

The general consensus among analysts tracking the e-learning market is that company success is tied to real business objectives (clomedia, 2003). A learning management system (LMS) implementation should be approached with the discipline, hard goals, timeline and performance benchmarks of any asset management project. One should not get confused by a laundry list of features usually provided by the content management systems companies. Focus should be on what the institution wants to accomplish from a business and an educational point of view and then identify needs.

In online learning, there seems to be two major research clusters where one deals with the development of good designs while the other deals with the assessment of student's satisfaction with an online course as it relates to a traditional face-to-face course. There is a sense of great expectations surrounding the development and use of online courses because of its versatility, flexibility and personalization potential. Many researchers today (Saadé, 2003; Poole \& Jackson, 2003; Shih, Munoz, \& Sanchez, 2006; Sunal, Sunal, Odell, \& Sundberg, 2003) are advocating that these expectation should be contrasted with proper empirical studies and rigorous results analysis evaluating the efficiency of the online learning courses that are being implemented. The implication to such type of research touches many domains due to the multi-dimensionality of online learning.

It is evident from the foregoing that the effort required for the learning management system is in designing and implementing appropriate learning strategy(ies) for the online courses. In fact, all of the CMSs available in the market include mainly features such as the standard forum, chat, linear and constant multiple choice question engine, standard wiki and centralized email. What these CMSs lack are tools that are based on some pedagogical principle which inherently include process as well.

As such, an online course should include different tools and should reflect pedagogy and instructional strategy. This article presents our work which addresses exactly this point of embedding pedagogy into the management of course content and presents the release 1.0 of an Efficient Learning Management System (ELMS) which was designed in-house and used with two courses in a higher education context. The design of the system is presented along with its architecture and components. Results of students' experiences using different learning objects are presented and discussed. Contribution to this research work is the (1) design of a scalable learning management system (2) pedagogical flexibility that is embedded in the system design and (3) in its highly interactive and collaborative environment. 


\section{The ELMS Application}

The Efficient Learning Management System (ELMS) is a web-based course components management system. It is not a simple 'source providing' and 'source retrieving' system, or 'content management system', but rather provides flexible courses management functionalities and systemic learning objects/tools (with measurable learning outcomes), such as (but not limited to) educational information system for enhanced learning (EISEL), virtual collaborative and peer-topeer testing environment (VLE), personalized mini-case development environment (PMDE), interactive computer aided learning (ICAL), higher order thinking skills tool (HOTS), and self maintaining forum (SMF).

These learning objects are part of a larger enterprise-wide learning management system with an integrated backend that allows 'data chunks' to be reused and recycled. The learning objects have been applied to real learning/teaching activities for the past 5 years. A major effort lasting for 8 months had been undertaken in 2006 to integrate all these learning objects into the enterprisewide learning management system. Together with service objects, role objects and interface objects, they form an interactive teaching/learning platform.

Due to limitation of space, we will present only some of the features, selected components and results. The design of ELMS is based on defined instructional, administrative and management activities. We present some of those activities and solutions as follows:

- Course generation: ELMS allow administrators to generate a course, and assign its instructor.

- User defining \& role assignment: Different users have different roles and different permissions to different components of ELMS. For example, at the beginning of a semester, an administrator gives authorizations for a professor to access a course. Professor then can manage content related to that course, such as define a TA for the course.

- Teaching Plan Scheduling: The course marking scheme is the central point for teaching plan scheduling in ELMS and the main view for the student. All teaching tasks and learning objects are organized in this view as shown in Figure 1.

Comm499i winter/2007 Course Marking Scheme.

\begin{tabular}{|c|c|c|c|}
\hline ID & Component & Weight & \\
\hline$\underline{1}$ & EISEL & 10 & description \\
\hline$\underline{2}$ & VLE & 20 & description \\
\hline$\underline{3}$ & Tests (Optional) & 5 & description \\
\hline$\underline{4}$ & MiniCases & 20 & description \\
\hline$\underline{5}$ & Final Exam & 45 & description \\
\hline$\underline{6}$ & Forum & 5 & description \\
\hline$\underline{7}$ & Questions Center & & description \\
\hline$\underline{8}$ & Media Portal & & description \\
\hline Total & & 105 & \\
\hline
\end{tabular}

Figure 1. Main course control panel for a specific course in ELMS.

- Content delivery: Learning content delivery includes announcements, lectures, and providing other relevant instructions such as instructions for assignments and projects. Students will be automatically reminded when learning content is published. 
- Regular learning interactivities for students: Regular interactivities are the most important components for students learning. ELMS provide many learning objects, such as EISEL, for students to understand course related material.

- Discussions between different participants: ELMS provides a forum-based platform for students, TAs and instructors to communicate and discuss relevant subject matter and cases with each other. Different from common forum, ELMS forum is well-defined and structured. Participation on forum is monitored by ELMS. Also, students can vote on different posts and when consensus is established, certain forum can be sent to the garbage bin or to the top 10 best discussions. Finally, a forum-participation report is automatically generated for instructors.

- Academic Reporting: In ELMS, academic report service helps instructors to create academic reports for students and allows students to check their activities and study result for each marking components for the course. ELMS summarize the academic results for the system components, which are pre-defined.

- Questions \& answers support tool: Questions and answers are an integral part of the learning activity. A flexible questions and answers service facility tool is provided. The question center provides an environment for students/TAs/professor(s) to collaboratively generate, answer and evaluate question-answer sets. This is an evolving knowledge management system.

\section{ELMS Prototype Design}

Firstly, ELMS is an object-classes objective system. All components in ELMS are classified into one of four types of objects: (1) role objects, (2) service objects, (3) reporting objects, and (4) learning object. For each type of objects, it has a unified interface, which can be easily plugged into ELMS by a relevant organizer. For ELMS defined objects, we define standard application frameworks. That means that the same type of objects have similar data structure. Secondly, ELMS is a database-driven system. The definition of each object is described in the database. Finally, ELMS is designed by model-view-controller (MVC) pattern.

\section{ELMS Architecture}

Figure 2 shows the ELMS architecture. ELMS entails five major components that identify different integrated solution for a true learning management system.

\section{(1) ELMS Management Center}

ELMS Management Center is the central module of ELMS. It interacts with other modules and controls the data flow and execution orders between the modules. It also is charged of initializing ELMS.

2 Learning objects \& Learning objects organizer

Learning objects are designed for regular learning activities for students. Each learning object has the same database hierarchy. A common interface is defined for each learning object. Learning objects organizer controls the behaviors of each learning object. When a learning request is retrieved in ELMS management center, a control message is passed into Learning objects organizer. Then Learning objects invoke relevant methods defined in learning objects interface. 


\section{Examples of learning objects}

- EISEL: Learning with EISEL, students go through the three system-guided following steps (repeated for many teacher defined subject matter): Pre-Test, Review resources, Practice related content, and Post-Test. Students first are evaluated on how much they know in a specific topic via the pre-test. They are then allowed to review and study the material related to the topic. When they are ready, students are allowed to practice the content using an interactive random generator multiple-choice and true-or-false engine. When students feel that they achieved the learning goals of the specific topic, they then complete a post-test to evaluate how much they have learned in this process. The system then opens access to the next topic or subject matter.

- VLE: VLE is a peer-to-peer collaborative testing system made up of three stages, and excludes the teacher intervention. This activity last for 3 days. In stage 1, students are randomly assigned a task, which they have to input a link pointing to a web page containing the results. They are then asked to evaluate their work and create a number of multiple choice questions related to the subject matter of that task (an example would be 'virtual memory'). In stage two, each student is given a link from one of his/her colleagues (randomly generated by computer) and asked to evaluate their work. Then students are provided with a set of multiple choice questions created in stage 1 to evaluate on level of difficulty and quality. Once this stage is completed, it is closed and an inference engine is run to generate a test which all students are asked to take (online). The inference engine ensures the selection of best quality questions and a pedagogically sound mix of three levels of difficulties. The system works well and the average through the 5 semesters that it has been used is consistently close to $70 \%$.

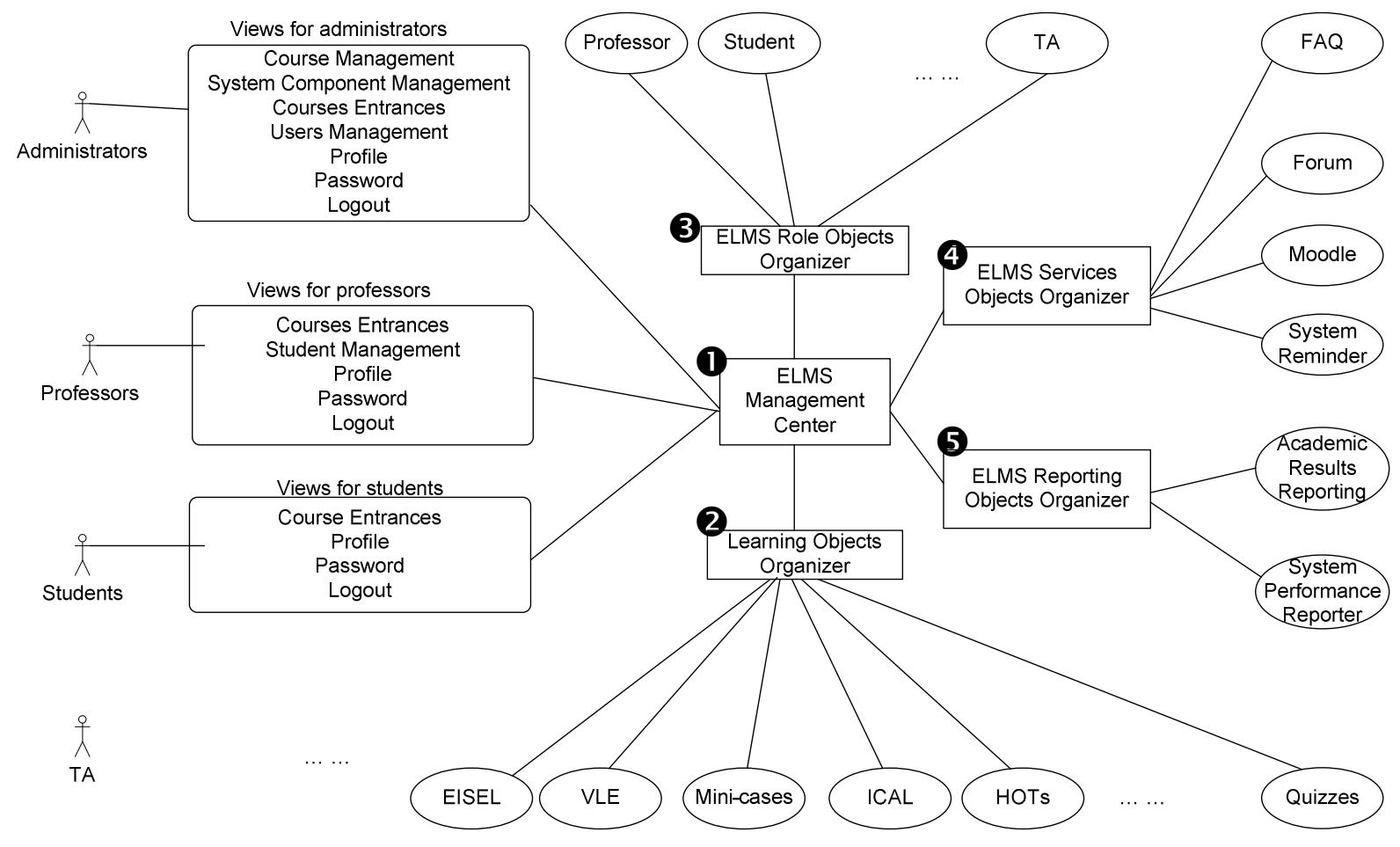

Figure 2. ELMS Architecture 
3 Role objects \& Role objects organizer

Role objects refer to different roles in ELMS, including administrator, instructor, student, teaching assistant (TA), technical assistant and moderator. User roles are treated as objects in ELMS. The behavior of role objects is mastered through role object organizer.

4 Service objects \& Service objects organizer

Service objects are a set of tools working with learning objects. They assist in the way learning objects behave, and provide a communication platform for users with different roles in ELMS. Communications between service objects and learning objects are accomplished by ELMS management center, service objects organizer, and learning objects organizer.

(5 Reporting objects \& Reporting objects organizer

Reporting objects provide convenient tools to generate system reports for instructors, administrators and students. A report object provides a type of reporting service. For example, academic reporter retrieves students' daily activities from learning objects, and generates reports. A reporting objects organizer is used to organize all report objects and communicate with learning objects.

\section{System Architecture \& Tools and Techniques}

Relevant tools and techniques used in ELMS are described below. Appropriate links to the main website of the technologies used are also provided.

- AJAX: AJAX, acronym of “Asynchronous JavaScript and XML”, is web development approach for interactive web applications development. It is first introduced by Jesse James Garrett in February 2005. Many large complex websites have chosen AJAX as a major approach to finish interactive information manipulation, such as Gmail. http://www.adaptivepath.com/publications/essays/archives/000385.php

- Microsoft IIS: Microsoft IIS is one of successful web server that provides a highly reliable, manageable and scalable Web application infrastructure for Microsoft Windows. As of February 2007 it served $31 \%$ of all websites according to Netcraft. http://www.microsoft.com/windowsserver2003/iis/default.mspx http://news.netcraft.com/archives/2007/02/02/february 2007 web server survey.html

- PHP: PHP (recursive acronym for "PHP: Hypertext Preprocessor") is a widely-used Open Source general-purpose scripting language that is especially suited for Web development and can be embedded into HTML. PHP can be deployed on most web servers and on almost every OS platform free of charge. The PHP Group also provides the complete source code for users to build, customize and extend for their own use. www.php.net

- MYSQL: MYSQL is the most popular open source database in the world now. www.mysql.com

- ASP: Active Server Pages (ASP) is a server-side scripting engine to generate web pages, introduced by Microsoft. Two scripting language are support by ASP - VB script and java script language. As an add-on to IIS, ASP usually runs on Microsoft's operation system. www.asp.net

- OOD and Design Pattern: Object-oriented design and design pattern are two important design approaches widely-used in software engineering. Object-oriented design takes the conceptual model that is the result of object-oriented analysis, then maps conceptual model to concrete classes, and abstract interfaces. The interfaces can be made available as reusable 
services. A design pattern is a general repeatable solution to a commonly occurring problem in software design.

http://en.wikipedia.org/wiki/Design_pattern_\%28computer_science\%29

The ELMS is -defined by the model-view-controller (MVC). Its model is represented by object classes, including learning objects, service objects, reporting objects and Role objects. Its view is represented by html and client side scripting language. The controller in ELMS is represented as a set of classes written by ASP or PHP, including ELMS manage center, learning objects organizer, service objects organizer, reporting objects organizer and Role objects organizer.

\section{ELMS Prototype - Release 1.0}

\section{Context}

ELMS design was frozen in December 2006 and labeled ELMS07V1for release 1.0. In January 2007, ELMS07V1 serviced two courses, Management Information System (MIS) and Fundamental of Information Technology (FIT), at the John Molson School of Business, Concordia University, Montreal, Quebec, Canada. 315 students were enrolled in the MIS core course and 215 students were taking the FIT optional elective course. Most students taking FIT were first semester students (newly admitted) while those taking the MIS courses were mostly second or third year students. Clearly the 'users' of the two courses imply the need to two different pedagogies and of course the context implies different course design constraints especially that MIS is a coordinated course with 5 other face-to-face sections being taught in the same semester.

Figure 3 provides a view of the main course interface. Administrators and professors would have different views reflecting what they have control in terms of course, content, communications and reporting management. The administrator has access to all courses in the system with the ability

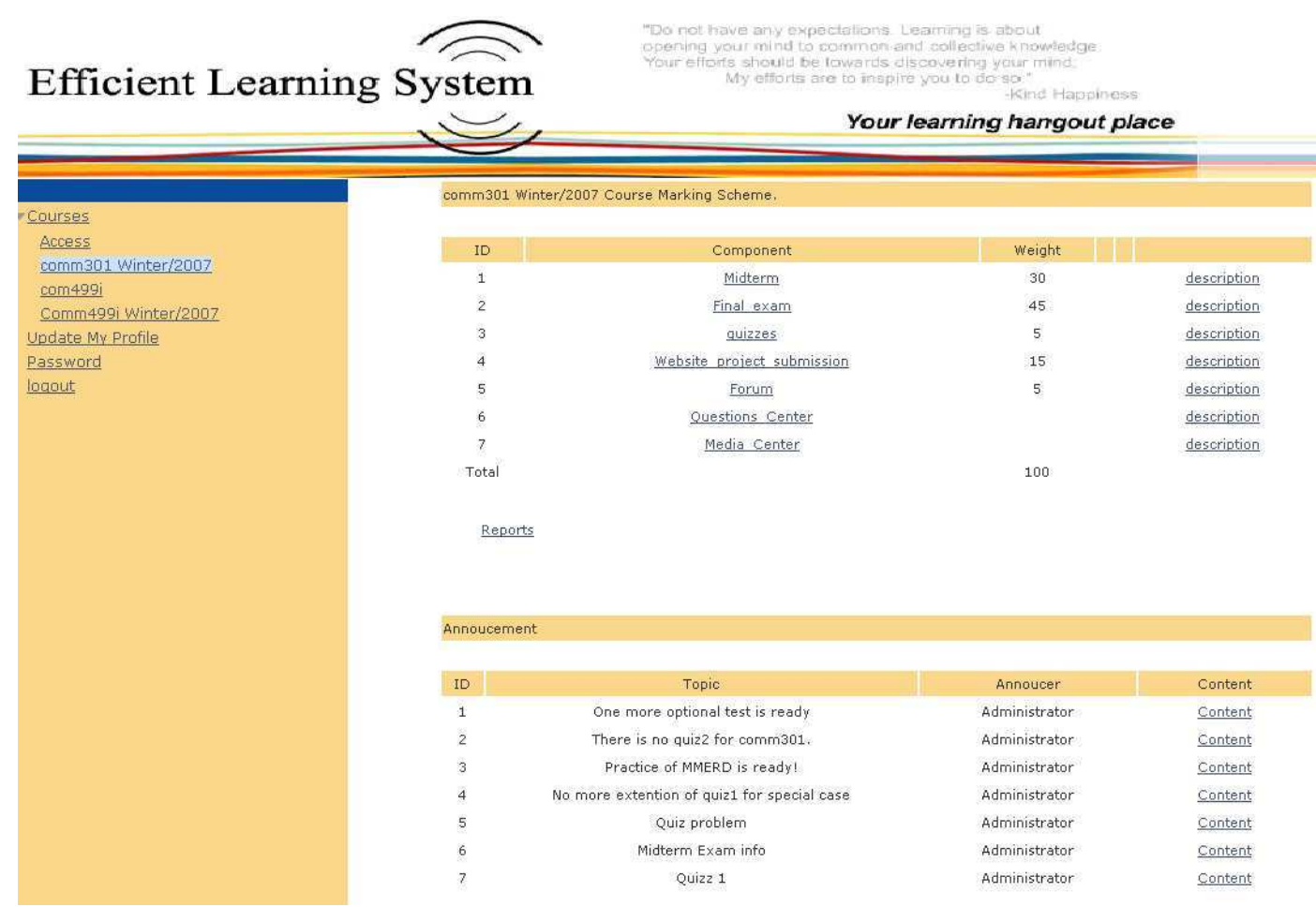

Figure 3. View of a student 
to create new one and build new ones from the ground-up by recycling other existing courses pieces. The teacher can access the course assigned to him/her and configure the activities and support tools in line (or not) with the course marking scheme. The TA is only a contributor to the assigned activities.

\section{Usage}

Comparing the two courses the FIT pedagogical design included more online activities and learning objects than the MIS course because the design concept for the FIT course is learn information technology by using information technology. So each learning object represents the use a different interface and the need to learn how to use it fast and become efficient with it. Additionally, the learning objects used with the FIT entail a significant amount of required weekly interactivity. Also as an example, the learning objects used such as the VLE is an inquiry based learning activity requiring the student to complete a task, evaluate his/her work, evaluate peer, create questions, and complete a test, in a seven step process. In terms of usage, and due to space constraints, we present some data on the question center and on the forum to simply demonstrate the amount of activity and interactivity that occurs in the online classroom. The question Center (used for the first time) results for both courses are presented in Table 1.

\begin{tabular}{|l|c|c|c|}
\hline \multicolumn{4}{|c|}{ Table 1. Question Center Statistics } \\
\hline Course & Students Total & $\begin{array}{c}\text { Total questions } \\
\text { generated }\end{array}$ & $\begin{array}{c}\text { Average question per } \\
\text { student (approximate) }\end{array}$ \\
\hline $\begin{array}{l}\text { Fundamental of In- } \\
\text { formation Technology }\end{array}$ & 215 & 234 & 1.0 \\
\hline MIS & 317 & 213 & 0.7 \\
\hline
\end{tabular}

The average questions generated for FIT was 1 per student, while for MIS was 0.7. These are the questions related to all possible topics such as course components, subject matter, exams, projects, etc... One would expect first semester students to ask more questions because of their unfamiliarity with the university system. Many of the questions by students taking FIT are course management related and to a lesser extent content related. The reverse is true with the MIS course. The question center included a satisfaction to the answer rating and most students were satisfied with the answers even when that required a few iterations.

Table 2 presents the participation in the EISEL learning object, but only for the practicing of questions part. EISEL is a system guided learning tool that navigates students from a post-test, to focused content, to practice and finally to post-test for 6 topics. This process from topic 1 to 6 is sequential such that topic 2 can only be started when topic 1 is completed, and so on to topic 6 . EISEL follows a scaffolding approach to content. EISEL was only used in the FIT course and for the period of 16 weeks. Table 2 shows that there is a significant amount of activity with EISEL. The average number of questions that a student practices in any specific week for any topic is 21 questions, which is approximately double the minimum guideline of 10 provided by the instructor for the course.

\begin{tabular}{|c|c|c|c|c|c|}
\hline \multicolumn{7}{|c|}{ Table 2. EISEL Practice Statistics } \\
\hline $\begin{array}{c}\text { Total } \\
\text { students }\end{array}$ & $\begin{array}{c}\text { Total } \\
\text { questions set }\end{array}$ & $\begin{array}{c}\text { Total } \\
\text { questions }\end{array}$ & $\begin{array}{c}\text { Practices } \\
\text { per week }\end{array}$ & $\begin{array}{c}\text { Total } \\
\text { practices } \\
\text { per day }\end{array}$ & $\begin{array}{c}\text { Total practice } \\
\text { per student } \\
\text { per day }\end{array}$ \\
\hline 215 & 14,953 & 74,765 & 4,672 & 667 & 3 \\
\hline
\end{tabular}


Looking at the VLE learning object, we present the top 5 best rated websites. These websites were rated the best by the students. This semester at least 25 students got to rate each and every website entered into VLE system. So the ranking is also a sort of consensus.

http://en.wikipedia.org/wiki/Computer_printer

http://systems.webopedia.com/TERM/P/printer.html

http://www.secretguide.net/read/index.php?filename=printers

http://www.computerhope.com/help/printers.htm

http://www.answers.com/topic/printer

Looking at the participation in the forum, Figures 4 and 5 present the number of posts students made in the forum on a weekly basis for the MIS and FIT courses respectively throughout the 16 weeks until the final exam time. Figures 4 and 5 clearly show that there was a significant increase in the forum activities during the last two week before the final exam. This increase can be estimated about 8 times and 11 times more than the average throughout the semester 13 week period for the MIS and FIT courses respectively. Comparing the two courses, students taking the MIS course participated slightly over double of the FIT students' in the last two weeks before the final exam. Similarly, on the average throughout the semester MIS students had double the participation that FIT students. That would be expected if the number of MIS students was double but in fact there was only about $47 \%$ more students taking the MIS course than the total FIT students. On the average, an MIS student had participated 50\% more than an FIT student. Regardless of the differences, student behavior pattern is the same across both courses.

Considering the data closer and for the 13 weeks of the course, the first evident finding is that the pattern in fact is not the same across the two courses. Although FIT students gradually increased their activities throughout the semester and peaking around the last week, MIS students had a two cycle behavior where their activities peaked in week 4 and week 10 .

These results are interesting and pertinent for course instructional strategy and for re-aligning the activities in relation to such aspects as mandatory versus optional and system guided versus flexible and student managed.

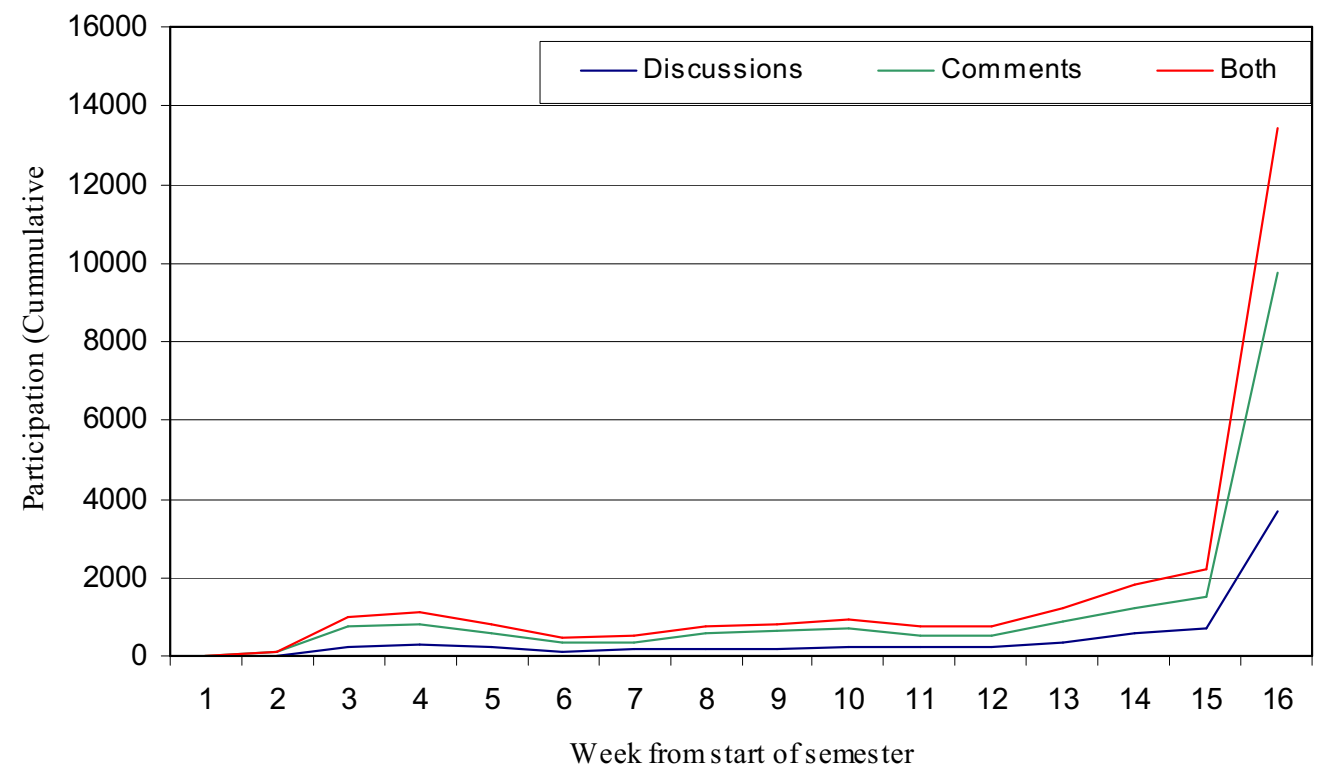

Figure 4. MIS Forum Participation 


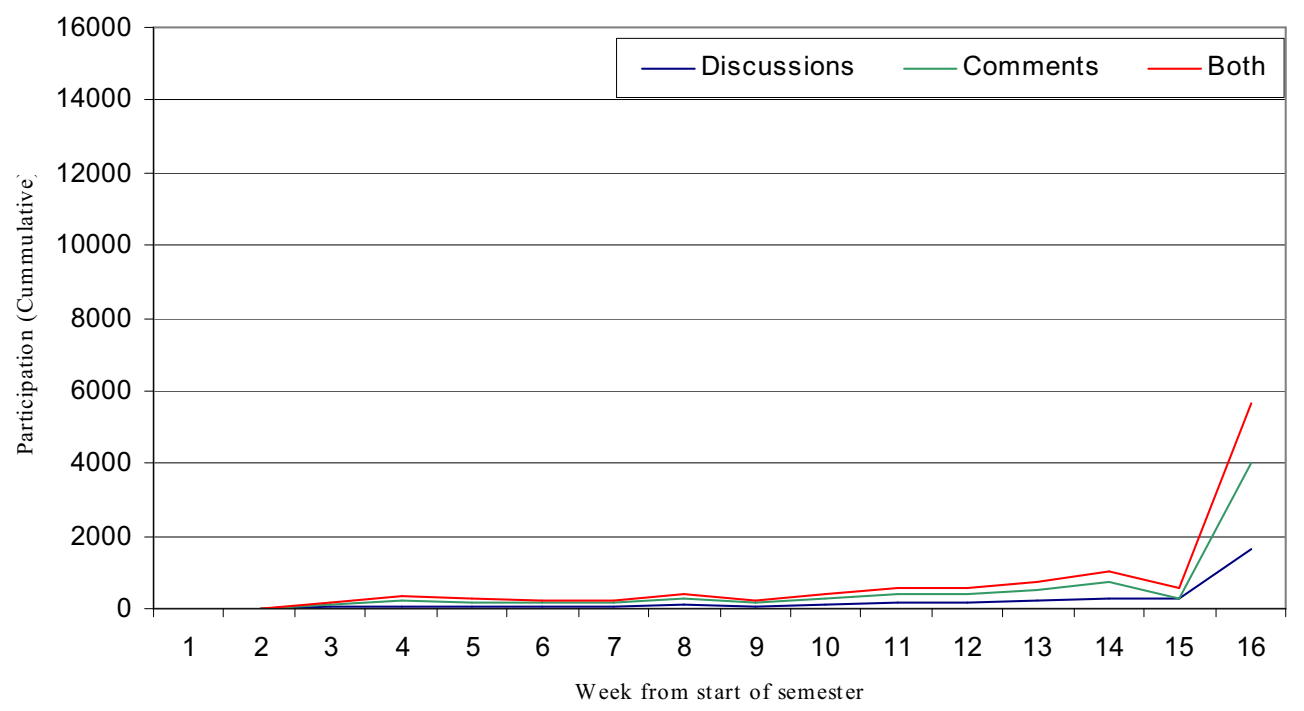

Figure 5. FIT Forum Participation

\section{Conclusion}

In this article, we presented an Efficient Learning Management System (ELMS) which was designed in-house and which was used to run two fully online courses in a higher education setup. The ELMS was a prototype used in a real time, real life mode. The system was used to run an MIS and an FIT course with 317 students in the first and 215 enrolled in the second.

The design of the system was presented along with its architecture and components. Results of students' experiences using EISEL, VLE and Forum were presented and discussed. It is clear from the results that the ELMS can accommodate different pedagogical designs, and can be used to not only measure student learning but also to understand their behavior. The differences between different groups and pedagogical designs are captured by the ELMS. Results show that students do participate and are interactive but they tend to gradually get into the learning mode as the semester progresses. Considering that the performance of the students online are within the range of the other 5 face to face sections, the ELMS has definitely provided a much better environment of interaction and participation overall, and hence the effort-to-learning ratio may be more.

The learning objects used are based on sound pedagogical principles such as inquiry based learning, and constructivism. The system was shown to promote individual critical thinking development and collaboration. The ELMS is designed for scalability, and recyclability of content and components.

This research work has made a serious attempt to question the content management system industry with respect to its learning value added. We made a 5 year effort to design of a true learning management system that can be scaled for an institutional setup and which draws on advanced computer-science techniques for its development. Our research work made it a point to have pedagogical flexibility embedded in the system design and ensure that whatever the course instructional design ends up to be, then it is operating in a highly interactive and collaborative envi- 
ronment. This clearly differentiates the concept of true online learning from the traditional distance learning.

\section{References}

Eklund, J., \& Eklund, P. (1996). Integrating the web and the teaching of technology: Cases across two universities. Proceedings of the AusWeb96, The Second Australian WorldWideWeb Conference, Gold Coast, Australia. Retrieved Feb, 2004 from http://wwwdev.scu.edu.au/sponsored/ausweb/ausweb96/educn/eklund2

Irani, T. (1998). Communication potential, information richness and attitude: A study of computer mediated communication in the ALN classroom. ALM Magazine, 2(1).

Poole, B. J., \& Jackson, L. (2003). Education online: Tools for online learning. In B. J. Poole, E. SkyMcIlvain, \& L. Jackson (Eds.), Education for an information age. Teaching in the computerized classroom $\left(4^{\text {th }}\right.$ ed. $)($ Chapter 9$)$.

Richardson, C. J., \& Swan, K. (2003). Examining social presence in online courses in relation to students' perceived learning and satisfaction. $J A L N, 7(1), 68-88$.

Saadé, G. R. (2003). Web-based educational information system for enhanced learning, (EISEL): Student assessment. Journal of Information Technology Education, 2, 267-277. Retrieved February 2004 from: http://jite.org/documents/Vol2/v2p267-277-26.pdf

Savenye, C. W., Olina, Z., \& Niemczyk, M. (2001). So you are going to be an online writing instructor: Issues in designing, developing and delivering an online course. Computers and Composition 18, 371385.

Shih, P., Munoz, D., \& Sanchez, F. (2006). The effect of previous experience with information and communication technologies on performance in a Web-based learning program. Computer and Human Behavior, 22(6), 962-970.

Sunal, W. D., Sunal, S. C., Odell, R. M., \& Sundberg, A. C. (2003). Research-supported best practices for developing online learning. The Journal of Interactive Online Learning, 2(1), 1-40.

\section{Biographies}

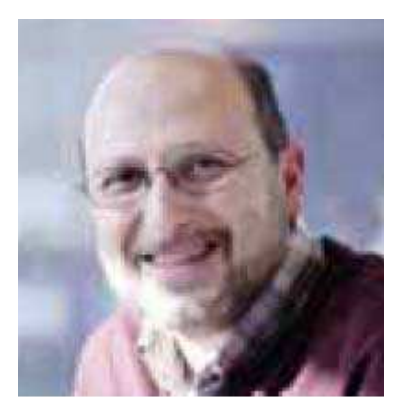

Dr. Raafat Saadé is a lecturer at the DSMIS department, John Molson School of Business, Concordia University, Canada. Dr. Saadé obtained his Ph.D. in 1995 from Concordia University. He subsequently received the Canadian National Research Council postdoctoral fellowship, which he completed at McGill University (Montreal). He has been recognized twice as a North Atlantic Treaty Organization ASI award winner. Dr. Saadé has 18 years of industrial experience (engineering, elearning and ehealth), and presently is involved in international consulting projects. He is very active in research with over 25 peer refereed journal articles. Dr. Saadé has published in top tier journals including Information \& Management, JISE, Expert Systems with Applications, and Decision Sciences.

Mr. Qiong Huang is a systems developer and analyst at the John Molson School of Business at Concordia University, Montreal. Mr. Huang has over 10 years of experience in China in the development of learning management systems. He is currently completing his masters in computer science at Concordia University. Mr. Huangs interests include the development of learning management systems and efficient algorithms in artificial intelligence. 